\title{
Swiss spring plant phenology 2007: Extremes, a multi-century perspective, and changes in temperature sensitivity
}

\author{
This Rutishauser, ${ }^{1,2}$ Jürg Luterbacher, ${ }^{1,2}$ Claudio Defila, ${ }^{3}$ David Frank, ${ }^{4}$ \\ and Heinz Wanner ${ }^{1,2}$ \\ Received 1 November 2007; revised 11 January 2008; accepted 24 January 2008; published 4 March 2008.
}

[1] Spring (March-May) 2007 was characterized by record high temperatures over European land areas. Anomalously high temperatures led to a very early onset of plant phenological spring phases, including 98 record early observations out of a possible total of 302 (32\%) for selected phases in Switzerland. In the context of the last 300 years and based on three tree species, 2007 marks the third earliest, after 1961 and 1794, plant phenological spring onset in Switzerland. We show that the temperature sensitivity of Swiss plant phenology to spring temperatures has changed within the last three centuries: sensitivity has generally increased over the record period but also decreased during two periods with warming trends (18901950; 1970-2007). Citation: Rutishauser, T., J. Luterbacher, C. Defila, D. Frank, and H. Wanner (2008), Swiss spring plant phenology 2007: Extremes, a multi-century perspective, and changes in temperature sensitivity, Geophys. Res. Lett., 35, L05703, doi:10.1029/2007GL032545.

\section{Introduction}

[2] Global land-surface temperature during spring (March-May) 2007 (SP07) was the warmest on record since 1880 [Smith and Reynolds, 2005; Hansen et al., 2001]. For the same period, Eurasia's snow cover extent was the 4th lowest in the 41-year measuring period. Above average precipitation fell over Scandinavia, France and the Mediterranean, whereas the central part of the U.K. and east-central Europe had less precipitation than the 1961-1990 reference period (www.ncdc.noaa.gov). Updated data by Xoplaki et al. [2005] indicate that the most recent spring is likely the warmest at the European land scale for more than 500 years. SP07 follows the exceptionally warm autumn 2006 and winter 2007-both extremely likely the warmest in Europe for the instrumental period [Beniston, 2007; van Oldenborgh, 2007; Yiou et al., 2007; Hirschi, 2008] and even the last half millennium [Luterbacher et al., 2007]. For the Swiss Geneva and Basel stations, SP07 was $1.1^{\circ} \mathrm{C}$ warmer than the 2nd warmest spring in 1755 [MeteoSwiss, 2007]. The warmth of the previous autumn and winter led to distinctly earlier flowering of plants, such as common hazel (Corylus avellana L.) and snowdrop (Galanthus nivalis), that typically flower in earliest spring [Luterbacher et al., 2007], and an early

\footnotetext{
${ }^{1}$ Institute of Geography and National Centre of Competence in Research Climate, University of Bern, Bern, Switzerland.

${ }^{2}$ Oeschger Centre for Climate Change Research, University of Bern, Bern, Switzerland.

${ }^{3}$ MeteoSwiss, Zurich, Switzerland.

${ }^{4}$ Swiss Federal Research Institute WSL, Birmensdorf, Switzerland.
}

Copyright 2008 by the American Geophysical Union. 0094-8276/08/2007GL032545 vegetation onset in general [Maignan et al., 2008]. Longterm temperature changes have left their 'fingerprints' across all seasons upon diverse floral and faunal phenology throughout Europe [e.g., Defila and Clot, 2001; Menzel et al., 2006]. Intergovernmental Panel on Climate Change (IPCC) [2007] showed that $90 \%$ of recorded biological systems worldwide display significant changes consistent with warming. In temperate zones, the timing of spring growth phases such as budding, leafing and flowering is mainly a response to accumulated temperature, or total heat, above a specific threshold [Peñuelas and Filella, 2001]. Experimental data for many plant species indicate that there is a linear relationship between the rate of development and temperature after release from winter dormancy above a heat threshold [e.g. Heikinheimo and Lappalainen, 1997]. Other studies utilized mean temperatures of the months previous to the event to quantify temperature forcing [e.g., Menzel, 2003]. Temperature sensitivity is often derived as the slope coefficient of a linear regression model in order to attribute phenological variability to temperature variability [e.g., Menzel et al., 2006; IPCC, 2007]. Menzel et al. [2006] detected a European wide temperature sensitivity of a large number of spring phenological phases of up to 4.6 days $/{ }^{\circ} \mathrm{C}$ advance with respect to the $1971-2000$ period. Flowering of many species in Britain advanced up to 25 days with a $2.5^{\circ} \mathrm{C}$ warming indicating a sensitivity of up to 10 days $/{ }^{\circ} \mathrm{C}[$ Fitter et al., 1995; Sparks et al., 2000]. However, regression modeling requires an a priori decision of the segment length that can lead to different inferences depending on the period of the regression [Tomé and Miranda, 2004]. To overcome this problem, moving window and running correlations in phenological applications have been applied for linear trends [e.g., Menzel et al., 2005; Rebetez and Reinhard, 2007; Rutishauser et al., 2007; Meier et al., 2007]. Long-term data sets are crucial to put findings of e.g., IPCC [2007] that assessed temperature sensitivity for the most recent decades into perspective. Here we present an updated Swiss phenological 'Spring plant' time series (1702-2007) and compare this record with long-term spring temperature measurements (1753-2007). These long records allow (1) the early SP07 phenological phases to be placed in the context of the past 300 years and (2) allow possible long-term trends and variability in temperature sensitivity to be assessed.

\section{Data and Methods}

[3] The 'Spring plant' phenological series for Switzerland 1702-2007 is defined as the annual mean day counted from January 1 for beech bud burst (Fagus sylvatica) and full flowering (FF) of the cherry (Prunus avium) and apple (Malus domesticus) tree [Rutishauser et al., 2007]. In 

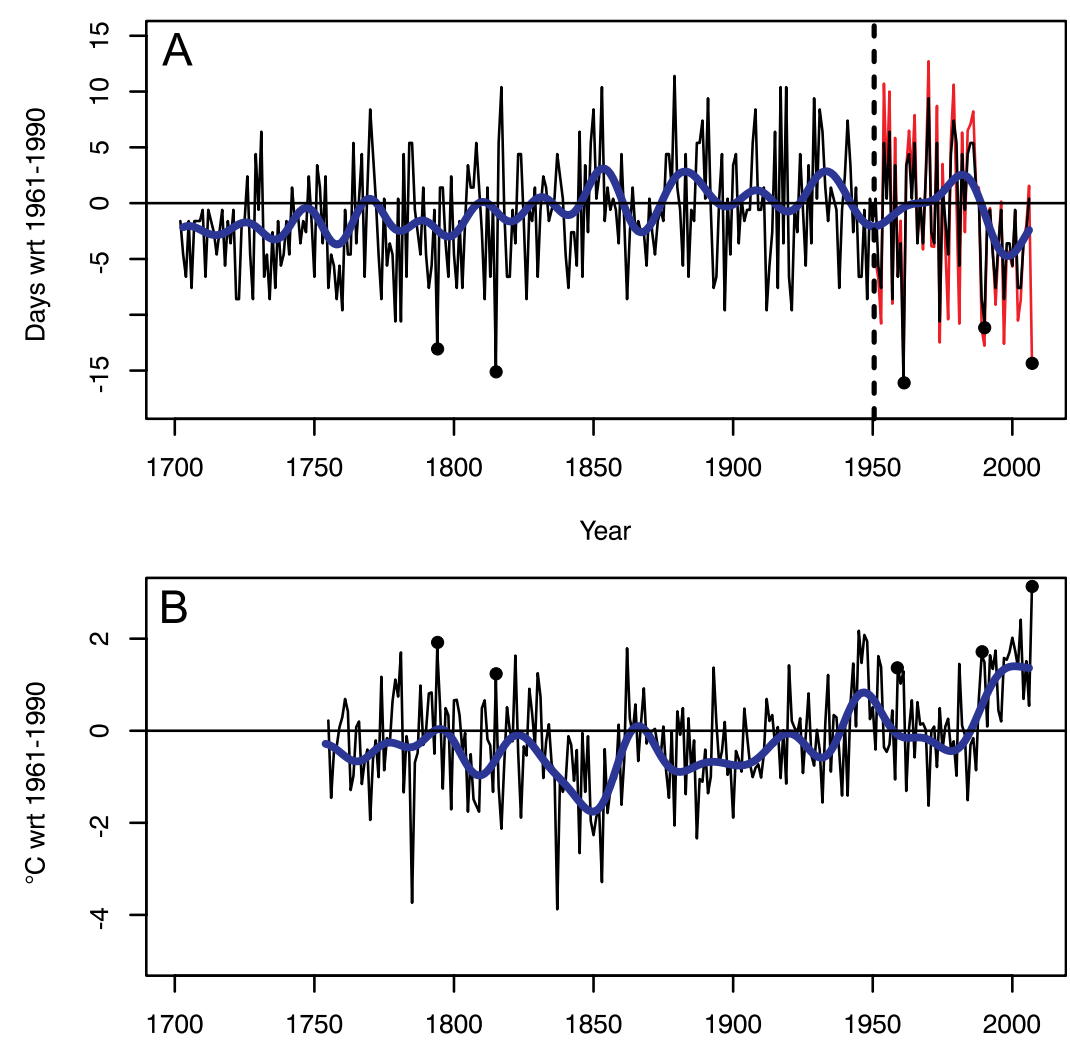

Figure 1. (a) Statistical reconstruction of a 'Spring plant' for Switzerland 1702-2007 in days deviating from the 19611990 reference period (horizontal line). Annual dates of the 'Spring plant' before (after) 1951 are reconstructed (observed within SPN) (thin black line) and the "Sofortmeldenetz" (1951-2007; red line). Blue line is a 20-year smooth "minimum roughness' constraint calculated according to Mann [2004]. The five earliest years were recorded in 1961, 1815, 2007, 1794, and 1990 (dots). (b) Swiss spring temperatures 1753-2007 as the averaged station means of Basel and Geneva from March-May. Dots highlight the same years as in (a).

Switzerland, these phases occurred on average on April 28, April 23, and May 7 during the 1951-2006 period. For the 1951-2006 period 'Spring plant' dates are based on 20-70 single observations per year from the Swiss Phenological Network (SPN) [Defila, 1991; Defila and Clot, 2001]. Within SPN, data are processed at the end of the growing season. However, the 'Spring plant' date for 2007 could be calculated from four selected stations that report in near real-time (i.e., the "Sofortmeldenetz") when a phase was observed. Before 1951 'Spring plant' dates are reconstructed from documentary observations of the same species [Rutishauser et al., 2007; C. Pfister and U. Dietrich-Felber (Eds.), Euro-Climhist: A data-base on past weather and climate in Europe and its human dimension, version 200602-01, available at www.euroclimhist.com]. Uncertainties of the phenological time series are $\pm 10( \pm 3.6)$ days at interannual (decadal) time scales [Rutishauser et al., 2007]. In addition to the three phenological phases averaged in the 'Spring plant', we analyze phenological observations from 38 stations from all Swiss regions for spring 2007 (www.meteoswiss.ch) [Defila, 1991]. Record early phenological phases of full flowering (FF, $50 \%$ of the flowers opened) and bud burst (BB, 50\% of leave buds open) reported by June 11 included common hazel (Corylus avellana L., FF), anemone (Anemone nemorosa, FF), horse chestnut (Aesculus hippocastanum, BB and FF), dandelion (Taraxacum officinale, FF), larch (Larix decidua, BB), daisy (Leucanthemum vulgare, FF), lime (Tilia platiphyllos, FF), pear (Pyrus communis, FF) and vine (Vitis vinifera, FF). Spring (MAM) mean instrumental temperatures are taken from the two Swiss stations of Geneva (starting 1753) and Basel (starting 1755) [Schüepp, 1961; Begert et al., 2005]. Monthly and seasonal European land anomaly temperature maps (with respect to the 1961-1990 reference period) are plotted with data from Xoplaki et al. [2005] and the most recent years (2003-2007) from the GISS/NASA analysis [Hansen et al., 2001]. A moving window linear regression approach was used to describe temperature sensitivity (slope coefficient) including the $95 \%$ confidence interval for each 30-year period.

\section{Results and Discussion}

[4] SP07 is the third earliest year recorded in plant phenological observations in Switzerland for the past 306 years (1702-2007; Figure 1a) derived from observed phenologybased statistical 'Spring plant' variability. Annual dates of the SPN (thin black line) and for selected immediately reporting stations are shown (red line). For the overlapping period 1951-2006, the four selected stations explain $92 \%$ of the variance $(\mathrm{p}<0.001)$ of the SPN 'Spring plant'. The five earliest years were recorded 1961, 1815, 2007, 1794 and 1990 (black dots). After 1990, the majority of years were earlier than the reference period [see also Studer et al., 2005]. SP07 was $3.1^{\circ} \mathrm{C}$ above the $1961-1990$ average and by far the warmest in the record back to 1753 (Figure 1b). SP07 was 
Spring

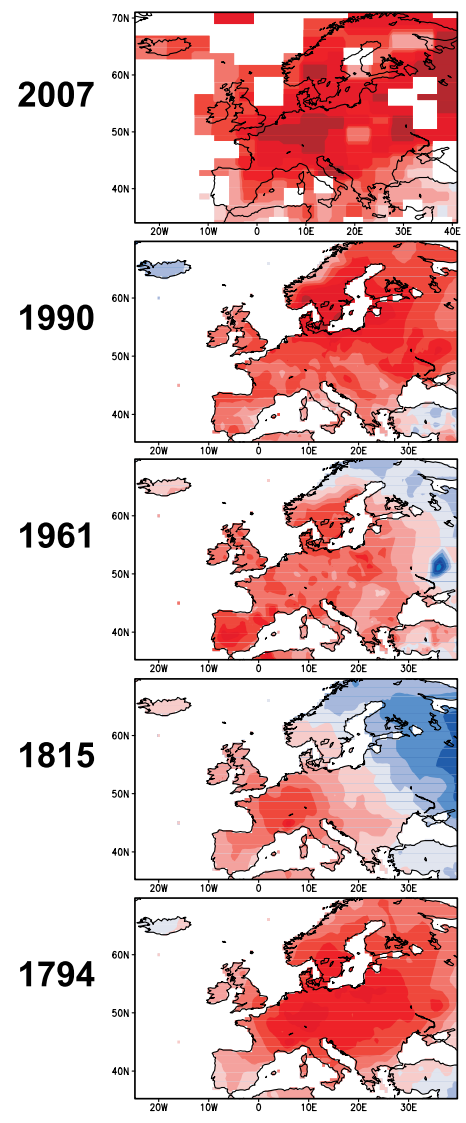

March
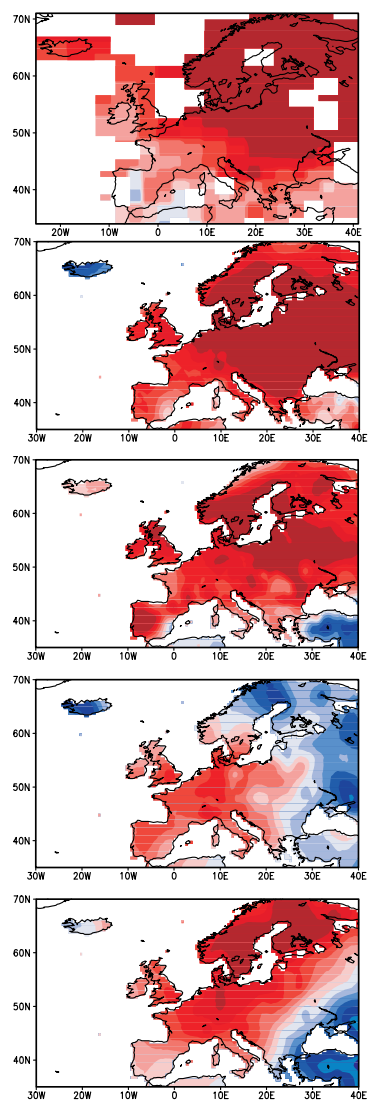

April
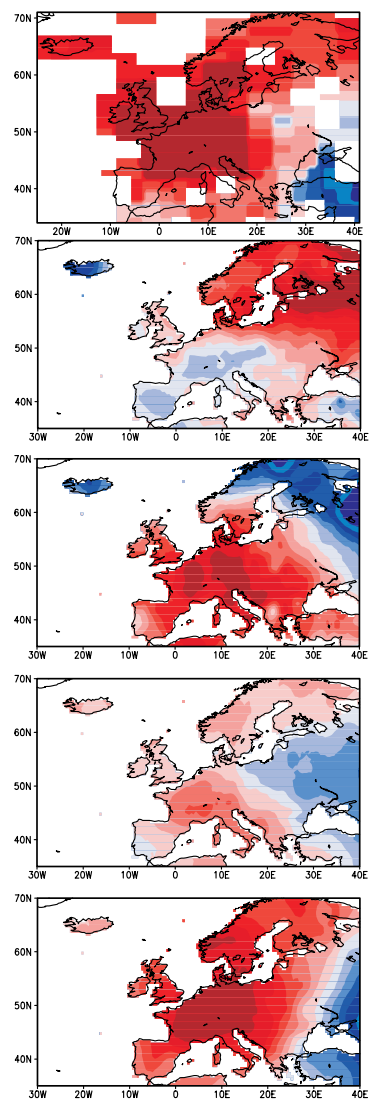

May
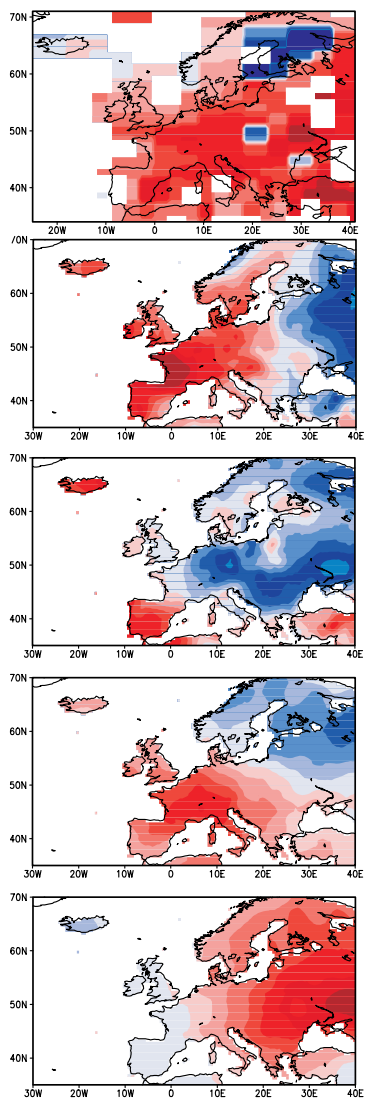

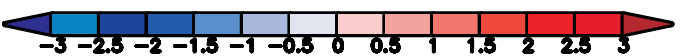

Figure 2. Temperature anomalies for the European land areas $\left(35^{\circ}-70^{\circ} \mathrm{N} ; 25^{\circ} \mathrm{W}-40^{\circ} \mathrm{E}\right)$ for the five selected years 1961 , 1815, 2007, 1794, and 1990 (with respect to 1961-1990) [Xoplaki et al., 2005; Hansen et al., 2001]. Spring (MAM) seasonal mean (first column) and contributing single months March-May (second-fourth columns) for the five selected years (rows) 1961, 1815, 2007, 1794, and 1990 from Figure 1.

$0.7^{\circ} \mathrm{C}$ warmer than the previously warmest spring of 2003 . April contributed most to the widespread positive temperatures (not shown) [MeteoSwiss, 2007]. 1794 also stands out with warmer temperatures matching the early phenological onset (Figure 1a) in agreement with independent phenological evidence from Germany [Chmielewski et al., 2004]. The three other springs $(1990,1961,1815)$ with exceptionally early plant phenological dates were related to positive temperature anomalies around $1^{\circ} \mathrm{C}$.

\section{Spatial and Intra-Seasonal Temperature Differences}

[5] For almost all European land areas positive anomalies of the order of $1{ }^{\circ} \mathrm{C}$ for spring 2007 were observed (Figure 2). Similar to autumn 2006 and winter 2007 [Luterbacher et al., 2007] the anomalous European SP07 warmth is associated with strong anticyclonic conditions over Europe and warm air advection from the central and subtropical Atlantic (not shown). The largest anomalies of $3^{\circ} \mathrm{C}$ are found in western and central Europe. In these regions all single months (March, April, May, Figure 2) contributed with positive anomalies to the seasonal spring mean. March was characterized by large areas of anomalies greater than $3^{\circ} \mathrm{C}$ over Eastern Europe and Scandinavia. In April positive anomalies extend from northern Spain to central Scandinavia and the British Isles to central Italy. May also had warm temperature anomalies of up to $2.5^{\circ} \mathrm{C}$ in specific European regions. All selected years of extremely early Swiss phenological observations $(1794,1815$, 1961, 1990, 2007) show widespread anomalously positive temperatures for western and central Europe (Figure 2, first column [Hansen et al., 2001; Xoplaki et al., 2005]). In addition, March and April temperatures for phenological extreme years were above the reference period mean (Figure 2, columns 2-3) except for April 1990. However, by comparing high temperatures with early phenological observations, it does not necessarily hold that exceptionally warm spring seasons lead to record early phenological observations. Considering single contributing months (Figure 2, columns 2-4), the three record years (2007, 1961, 1794) show continuously very warm March and April temperature anomalies. 1794 shows only weak warming anomalies. 1961 depicts cold May temperature anomalies of up to $-3^{\circ} \mathrm{C}$ over central Europe whereas 2007 continuous with strong warm anomalies until May. Subseasonal processes such as cold spells and frost, local peculiarities, extremes in precipitation and the complexity of plant physiological 

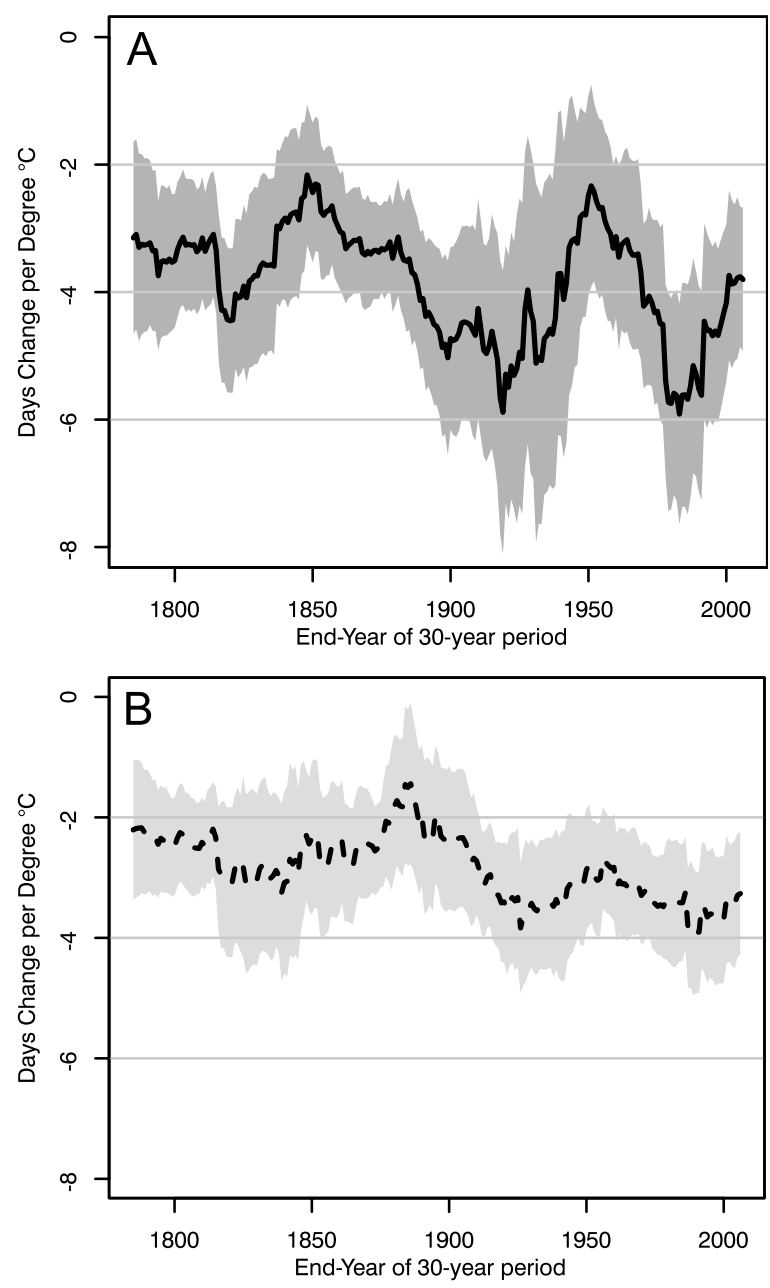

Figure 3. Moving temperature sensitivity of Swiss 'Spring plant' [Rutishauser et al., 2007] to (a) Swiss spring (MAM) and (b) late-winter (FMA) temperatures [Begert et al., 2005]. 2-standard deviation range shows $95 \%$ confidence interval for spring and late-winter sensitivity coefficients.

processes [Larcher, 2003] lead to uncertainties and variability in monthly and seasonal temperature means and impacts upon phenology.

\section{Phenological Extremes 2007}

[6] Strong phenological response is not only seen in the mean state of Swiss spring phenology as shown by the 'Spring plant' but also by record early observations in many plant species and phenological phases. 98 new record early observations of single species and phases out of a possible total of 302 in total were observed at 38 stations. Most of these records were reported for north of the Alps, central Switzerland and the Engadine valley/southeastern Switzerland. Furthermore, full flowering of the cherry tree in Liestal, Switzerland [Defila and Clot, 2001] continuously observed since 1894 indicated the earliest flowering of the record -28 days earlier than the long-term mean. In Germany, phenological development of SP07 showed advances of up to three months for agricultural phases such as winter wheat (Triticum spp.) and oilseed canola (Brassica napus). In the end, these plants flowered 2.5 weeks earlier than normal
[Deutscher Wetterdienst (DWD), 2007]. Spring 2007 was very early even with respect to the already early spring development of the 15 preceding years (1992-2006). Wild plant phases showed slower development compared to agricultural phases despite warm temperatures $[D W D$, 2007]. In the Netherlands, early flowering dates-associated with record high temperatures and April being $5^{\circ} \mathrm{C}$ above the mean-were observed for several herbs and flowers (www.natuurkalender.nl; Figure 2). In France, the exceptionally mild winter and spring caused a broad advance in annual crop species, fruit trees and grape phenology with a general range of 1 to 3 weeks (B. Seguin, personal communication, 2007). Spring phenological observations broadly indicate one of the earliest springs in the UK (N. Collinson and T. Sparks, BBC Spring Watch 2007, report as at 16 May 2007 downloaded from www.naturescalendar. org.uk, accessed 6 July 2007): Hawthorn flowers were first seen almost a month earlier than normal and three weeks earlier than last year. However, the phenological observations of the Marsham family [Sparks and Carey, 1995] show the earliest onset for all plant phenological phases in 1794 (no observations in 1815). This year was only outdone by 1779 in the UK and is also in agreement with the 'Spring plant' record for Switzerland [Rutishauser et al., 2007]. It should be noted that such spatial comparisons of extremes in historical records are challenging, especially before the start European network observations, because of scarce observations.

\section{Temperature Sensitivity}

[7] Temperature sensitivity for Swiss spring seasons expressed as the coefficient of linear regression models has varied between 6 days/degree (1890-1920, 1950-1980) and 2 days/degree ${ }^{\circ} \mathrm{C}(1820-1850,1920-1950)$ to spring (MAM) season temperature (Figure 3a). 2-standard error range includes the confidence interval of the estimated sensitivity coefficient from linear sensitivity regression models (grey shading). The uncertainty bands do not overlap for the 1946-1975 and 1926-1955 periods despite nine common years. However, sensitivity to late-winter (FMA) temperatures is generally lower and only changes between $2-4$ days $/{ }^{\circ} \mathrm{C}$ (Figure 3b). For the latest 30-period, spring temperature sensitivity has decreased to 4 days $/{ }^{\circ} \mathrm{C}$ in the 1977-2006 period whereas sensitivity to late-winter temperatures remained stable. Temperature sensitivity before 1900 is more stable and generally lower than during the 20th century. Even though there is a general trend towards higher temperature sensitivity over the whole record, lowered sensitivity to spring temperature is indicated in the periods with warming trends, namely $1890-1950$ and $1970-2007$. While the long-term trend of increasing sensitivity towards present is consistent with similarly increasing proxy and instrumental quality [Frank et al., 2007], such factors however could not explain the multi-decadal fluctuations in sensitivity. Menzel et al. [2005] also compared temperature sensitivity for eight stations and three phenophases (beginning of flowering in the horse chestnut (Aesculus hippocastanum), lilac (Syringa vulgaris), and red currant (Ribes rubrum)) across Germany for 1900-1950 and 1951-2000. They found that most cases do not show significant differences between the first and second half of the 20th century. "Rare relevant cases" 
[Menzel et al., 2005] display large sensitivities for both periods. Menzel et al. [2005] concluded that there are no systematic differences in the temperature response rates in the first and second half of the last century. However Figure 3 demonstrates that the periods of changing temperature sensitivity strongly depends on the selection of the period endings. Our analysis reveals significant changes if we include the two 30-years periods before and after 1950 .

\section{Conclusions}

[8] We presented interannual coevolution of plant phenology and spring temperature for the period 1753-2007, and have shown that temperature variability distinctly impacted spring phenological development in Switzerland for the past 300 years. The extremely high temperatures in SP07 were fingerprinted on phenological phases across Europe. However, not all species and phases reacted identically. In addition, we demonstrated that temperature sensitivity of plant phenology to spring and late-winter mean temperatures has changed over the past three centuries. It remains open to disentangle other long-term influences including land cover, land use, agricultural practices and succession as well as other meteorological and environmental parameters, such as precipitation, soil properties, and water availability, snow cover that may contribute to intraseasonal decoupling of phenological development and temperature. Mechanistic prognostic modelling will further contribute to the understanding of phenology-climate related exchange processes as differences for single years such as 1973, 1989 and 1990 can be analysed with a plethora of daily resolved input variables.

[9] Acknowledgments. This research is supported by the Swiss NSF (project contract number 205321-105691/1) and NCCR-Climate. The Foundation Marchese Francesco Medici del Vascello financially supported the publication. Personal communications of B. Séguin, A. van Vliet and T. Sparks translations of Annemieke Stössel and comments of Reto Stöckli, the editor and two anonymous reviewers are acknowledged.

\section{References}

Begert, M., T. Schlegel, and W. Kirchhofer (2005), Homogeneous temperature and precipitation series of Switzerland from 1864 to 2000, Int. J. Climatol., 25, 65-80.

Beniston, M. (2007), Entering into the 'greenhouse century': Recent record temperatures in Switzerland are comparable to the upper temperature quantiles in a greenhouse climate, Geophys. Res. Lett., 34, L16710, doi:10.1029/2007GL030144.

Chmielewski, F.-M., A. Müller, and E. Bruns (2004), Climate changes and trends in phenology of fruit trees and field crops in Germany, 19612000, Agric. For. Meteorol., 121, 69-78.

Defila, C. (1991), Pflanzenphänologie der Schweiz, Veröff. Schweizer. Meteorol. Anst., vol. 50, 235 pp., Schweizer. Meteorol. Anst., Zurich, Switzerland.

Defila, C., and B. Clot (2001), Phytophenological trends in Switzerland, Int. J. Biometeorol., 45, 203-207.

Deutscher Wetterdienst (DWD) (2007), Was ist mit dem Wetter los?, Phänologie J. 28, Offenbach, Germany.

Fitter, A. H., R. S. R. Fitter, I. T. B. Harris, and M. H. Williamson (1995), Relationship between first flowering date and the temperature in the flora of a locality in Central England, Funct. Ecol., 9, 55-60.

Frank, D., U. Büntgen, R. Böhm, M. Maugeri, and J. Esper (2007), Warmer early instrumental measurements versus colder reconstructed temperatures: Shooting at a moving target, Quat. Sci. Rev., 26, 3298-3310.

Hansen, J., R. Ruedy, M. Sato, M. Imhoff, W. Lawrence, D. Easterling, T. Peterson, and T. Karl (2001), A closer look at United States and global surface temperature change, J. Geophys. Res., 106, 947-963.

Heikinheimo, M., and H. Lappalainen (1997), Dependence of the flower bud burst of some plant taxa in Finland on effective temperature sum: Implications for climate warming, Ann. Bot. Fenn., 34, 229-243.
Hirschi, J. J.-M. (2008), Unusual North Atlantic temperature dipole during the winter of 2006/2007, Weather, 63, 4-11.

Intergovernmental Panel on Climate Change (IPCC) (2007), Working Group II Contribution to the Intergovernmental Panel on Climate Change Fourth Assessment Report. Climate Change 2007: Climate Change Impacts, Adaptation and Vulnerability. Summary for Policymakers, Cambridge Univ. Press, New York.

Larcher, W. (2003), Physiological Plant Ecology: Ecophysiology and Stress Physiology of Functional Groups, Springer, New York.

Luterbacher, J., M. A. Liniger, A. Menzel, N. Estrella, P. M. Della-Marta C. Pfister, T. Rutishauser, and E. Xoplaki (2007), Exceptional European warmth of autumn 2006 and winter 2007: Historical context, the underlying dynamics, and its phenological impacts, Geophys. Res. Lett., 34, L12704, doi:10.1029/2007GL029951.

Maignan, F., F. M. Bréon, E. Vermote, P. Ciais, and N. Viovy (2008), Mild winter and spring 2007 over western Europe led to a widespread early vegetation onset, Geophys. Res. Lett., 35, L02404, doi:10.1029/ 2007GL032472.

Mann, M. E. (2004), On smoothing potentially non-stationary climate time series, Geophys. Res. Lett., 31, L07214, doi:10.1029/2004GL019569.

Meier, N., T. Rutishauser, C. Pfister, H. Wanner, and J. Luterbacher (2007), Grape harvest dates as a proxy for Swiss April to August temperature reconstructions back to AD 1480, Geophys. Res. Lett., 34, L20705, doi:10.1029/2007GL031381.

Menzel, A. (2003), Plant phenological anomalies in Germany and their relation to air temperature and NAO, Clim. Change, 57, 243-263.

Menzel, A., N. Estrella, and A. Testka (2005), Temperature response rates from long-term phenological records, Clim. Res., 30, 21-28.

Menzel, A., et al. (2006), European phenological response to climate change matches the warming pattern, Global Change Biol., 12, 1969-1976.

MeteoSwiss (2007), Monthly climate and weather reports, Zurich, Switzerland.

Peñuelas, J., and I. Filella (2001), Response to a warming world, Science, 294, 793-795.

Rebetez, M., and M. Reinhard (2007), Monthly air temperature trends in Switzerland 1901-2000 and 1975-2004, Theor. Appl. Climatol., doi:10.1007/s00704-007-0296-2.

Rutishauser, T., J. Luterbacher, F. Jeanneret, C. Pfister, and H. Wanner (2007), A phenology-based reconstruction of interannual changes in past spring seasons, J. Geophys. Res., 112, G04016, doi:10.1029/ 2006JG000382.

Schüepp, M. (1961), Lufttemperatur. Langjährige Temperaturreihen, Beih. Ann. Schweiz. Meteorol. Zentralanst., Zurich, 2, 48.

Smith, T. M., and R. W. Reynolds (2005), A global merged land air and sea surface temperature reconstruction based on historical observations (1880-1997), J. Clim., 18, 2021-2036.

Sparks, T. H., and P. D. Carey (1995), The responses of species to climate over two centuries: An analysis of the Marsham phenological record 1736-1947, J. Ecol., 83, 321-329.

Sparks, T. H., E. P. Jeffree, and C. E. Jeffree (2000), An examination of the relationship between flowering times and temperature at the national scale using long-term phenological records from the UK, Int. J. Biometeorol., 44, 82-87.

Studer, S., C. Appenzeller, and C. Defila (2005), Interannual variability and decadal trends in Alpine spring phenology: A multivariate analysis approach, Clim. Change, 73, 395-414.

Tomé, A. R., and P. M. A. Miranda (2004), Piecewise linear fitting and trend changing points of climate parameters, Geophys. Res. Lett., 31, L02207, doi:10.1029/2003GL019100.

van Oldenborgh, G. (2007), How unusual was autumn 2006 in Europe?, Clim. Past, 3, 659-668.

Xoplaki, E., J. Luterbacher, H. Paeth, D. Dietrich, N. Steiner, M. Grosjean, and $\mathrm{H}$. Wanner (2005), European spring and autumn temperature variability and change of extremes over the last half millennium, Geophys. Res. Lett., 32, L15713, doi:10.1029/2005GL023424.

Yiou, P., R. Vautard, P. Naveau, and C. Cassou (2007), Inconsistency between atmospheric dynamics and temperatures during the exceptional 2006/2007 fall/winter and recent warming in Europe, Geophys. Res. Lett., 34, L21808, doi:10.1029/2007GL031981.

C. Defila, MeteoSwiss, Krähbühlstrasse 58, CH-8044 Zurich, Switzerland. D. Frank, Swiss Federal Research Institute WSL, Zuercherstrasse 11, CH-8903 Birmensdorf, Switzerland.

J. Luterbacher, T. Rutishauser, and H. Wanner, Institute of Geography and NCCR Climate, University of Bern, Hallerstrasse 12, CH-3012 Bern, Switzerland. (rutis@giub.unibe.ch) 